\title{
Preliminary study on genetic variation of growth traits and wood properties and superior clones selection of Populus ussuriensis Kom.
}

\author{
Jiaojiao Jin, \\ Xiyang Zhao, \\ Huanzhen Liu, \\ Sui Wang, \\ Ziwen Song, \\ Xiaoyu Ma, \\ Kailong Li
}

\begin{abstract}
In this study the genetic variation of growth traits and wood properties was assessed in 45 clones of Populus ussuriensis Kom. grown in a 10-year-old experimental forest located in Northeastern China and a preliminary selection of superior clones was performed based on multi-trait selection index. The following traits were analyzed: tree height, $\mathrm{H}$; diameter at breast height, $\mathrm{DBH}$; volume, V; basic wood density, BWD; fiber length, FL; fiber length-width ratio, FL/W; microfibril angle, MA; cell wall percentage, CWP; fiber double wall thickness, FWT; vessel proportion, VP; wood fiber proportion, FP; wood ray proportion, RP; holocellulose content, HC. The results revealed significant differences $(P<0.05)$ in DBH, V, BWD, FWT, VP and FP among different clones. Broad-sense heritabilities for growth traits and wood properties ranged from 0.020 to 0.749 , therefore growth traits and wood properties are moderately or weakly controlled. Negative correlations between growth traits and most wood properties were also found. According to the multi-trait selection index at a selected rate of $10 \%$ and survival rates, 3 superior clones $(\mathbf{I 1 8}, \mathrm{H} 16, \mathrm{C} 13)$ were selected, and the DBH, V, BWD, FL and FP of superior clones were higher than those of all clones by $2.83 \%, 9.81 \%, 3.40 \%, 6.59 \%$ and $0.31 \%$, the $M A$, FWT, VP were lower than those of all clones by $7.54 \%, 0.39 \%, 2.12 \%$, respectively. These superior clones could be used as starting breeding material for $P$. ussuriensis.
\end{abstract}

Keywords: Populus ussuriensis Kom., Growth Traits, Wood Properties, Genetic Variation, Multi-trait Index Selection from natural forests. Indeed, the area covered by mature forests decreased since 2000 (Sloan \& Sayer 2015). Whether they can continue to provide enough goods and services is a worry. In contrast, the demand for industrial wood and firewood is increasing. With the implementation of natural forest protection projects in China, wood products such as timber are now mainly dependent on plantations. Hence, there is an urgent need for fast-growing, high-quality plantations.

Populus ussuriensis Kom. has a strong adaptability and very high yield. It is also suitable for adjusting stand structure in commercial forest plantations (Wang et al. 2003). In addition, it is one of the main tree species of forest renewal in the eastern $\square$ State Key Laboratory of Tree Genetics and Breeding, Northeast Forestry University, Harbin, 150040 (China)

@ Kailong Li (yzlkl123@126.com)

Received: Nov 14, 2018 - Accepted: Jul 18, 2019

Citation: Jin J, Zhao X, Liu H, Wang S, Song Z, Ma X, Li K (2019). Preliminary study on genetic variation of growth traits and wood properties and superior clones selection of Populus ussuriensis Kom. iForest 12: 459-466. - doi: 10.3832/ifor2991-012 [online 2019-0929]

Communicated by: Fulvio Ducci mountainous areas of Northeastern China. P. ussuriensis is widely distributed in Northern China, the Korean Peninsula and the Far East (Zhou et al. 1986). It grows mainly in the mountains at an altitude of 300-1200 $\mathrm{m}$ a.s.l. on slightly acidic brown forest soil or mountain dark brown soil. P. ussuriensis has straight trunk and the durability of white timber, and it is an important resource for construction, paper and plywood. Zhang et al. (1996) studied the fiber morphology and basic density of $P$. ussuriensis, finding that it can meet the requirements of pulpwood. Furthermore, Wang et al. (2011) found significant differences in $\mathrm{H}$, $\mathrm{DBH}$ and $\mathrm{V}$ among clones of $P$. ussuriensis.

The properties of poplar wood have a deep effect on its industrial use. Indeed, large differences in wood properties has been found among different poplar clones, between different individuals of the same clone and also between different parts of the same individual tree. Such differences are largely influenced by site conditions, cultivation measures and other factors in a complex way. Up to now, studies about the physical properties of poplar wood mainly focused on wood density, moisture content and shrinkage rate. For example, Li \& Xu (1994) found a significant linear positive correlation between wood density at breast height and the density of the whole tree in the poplar clone I-63. Xing \& Zhang (2004) studied triploid Chinese white pop- 


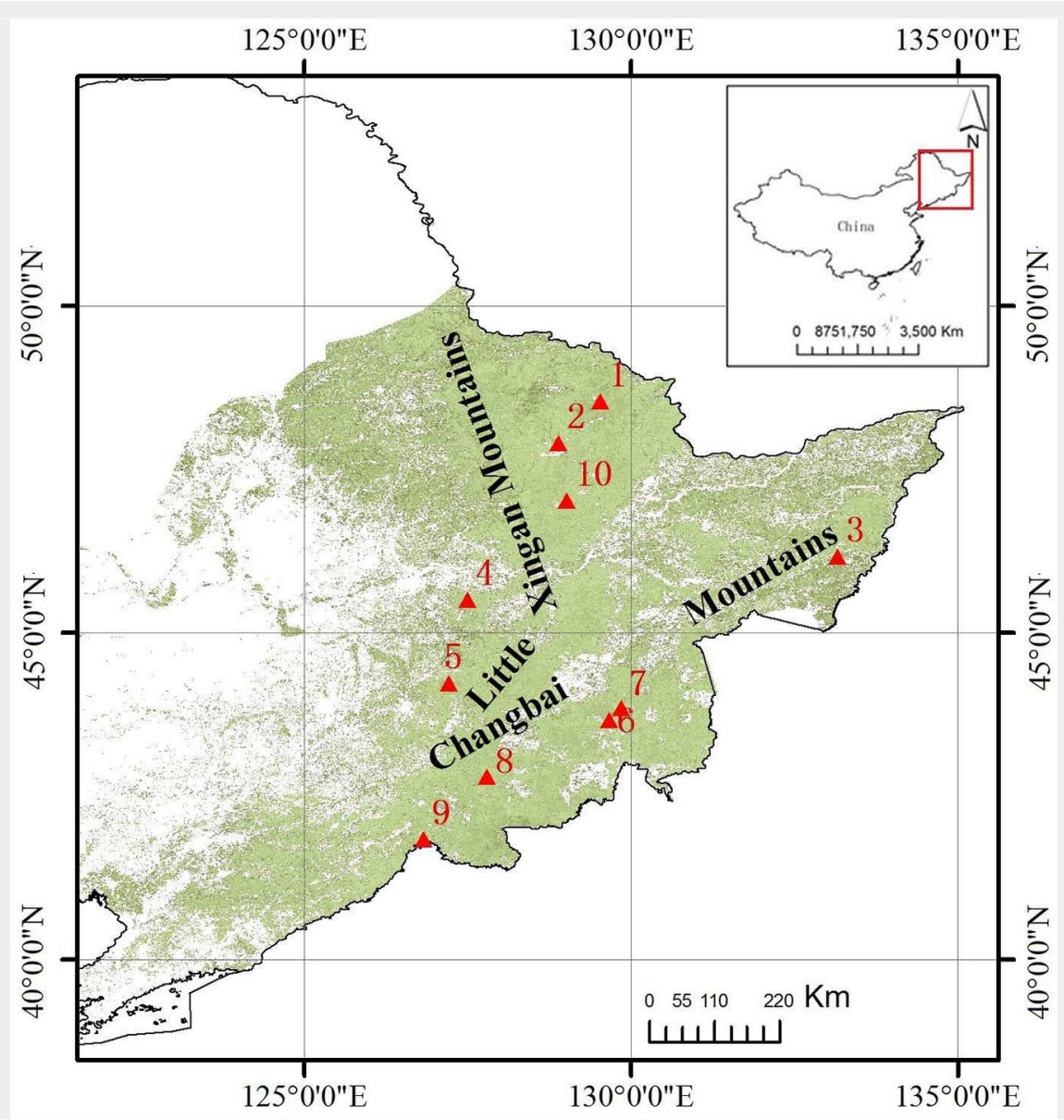

Fig. 1 - The natural range of $P$. ussuriensis in Northeastern China (in green) and the original sampling locations of clones (red triangles). For each location, the site name and the clones collected therein are listed below. (1): Xinqing - D9, F6; (2): Yichun E5, E8, E9; (3): Dongfanghong - J9, J19, J20; (4): Maoershan - M10, M13, M14, M15, M16, M17, M19, M20; (5): Shangying - D16, D17; (6): Jiangshanjiao - H4, H5, H7, H8, H12, H13, H16; (7): Wangqing - D13, I5, I8, I10, I18; (8): Lushuihe - B5, B6, B8, D5, D11; (9): Linjiang - C1, C9, C12, C13, C14, C15, C16; (10): Dailing - D22, D23, D24. Maoershan (4) is the experimental site at the Northeast Forestry University (Heilongjiang).

lar and showed that arid shrinkage rate of with variation patterns in the longitudinal wood was significantly different between direction decreasing with the increment of clones and strongly controlled by genes, tree height. Yanchuk et al. (1984) showed a

Tab. 1 - The survival rates of 45 poplar (P. ussuriensis) clones analyzed in this study.

\begin{tabular}{|l|lllll|}
\hline Clone & $\begin{array}{c}\text { Survival } \\
\text { rate (\%) }\end{array}$ & Clone & $\begin{array}{l}\text { Survival } \\
\text { rate (\%) }\end{array}$ & Clone & $\begin{array}{c}\text { Survival } \\
\text { rate (\%) }\end{array}$ \\
\hline I10 & 95.24 & F6 & 80.95 & J20 & 73.81 \\
\hline B5 & 92.86 & H13 & 80.95 & C9 & 69.05 \\
\hline B8 & 92.86 & H5 & 80.95 & D11 & 69.05 \\
\hline M20 & 92.86 & H7 & 80.95 & I5 & 69.05 \\
\hline M19 & 90.48 & J9 & 80.95 & D23 & 64.29 \\
\hline C14 & 88.10 & C13 & 78.57 & E9 & 64.29 \\
\hline M14 & 88.10 & D13 & 78.57 & H12 & 64.29 \\
\hline C16 & 85.71 & D22 & 78.57 & C15 & 61.90 \\
\hline D24 & 85.71 & M15 & 78.57 & I8 & 59.52 \\
\hline M10 & 85.71 & I18 & 76.79 & C12 & 57.14 \\
\hline M17 & 85.71 & B6 & 76.19 & H4 & 57.14 \\
\hline D16 & 83.33 & M13 & 76.19 & E5 & 52.38 \\
\hline D17 & 83.33 & M16 & 76.19 & J19 & 52.38 \\
\hline H8 & 83.33 & D5 & 73.81 & C1 & 47.62 \\
\hline D9 & 80.95 & H16 & 73.81 & E8 & 47.62 \\
\hline
\end{tabular}

slight negative phenotypic correlation between wood density and growth rate in trembling aspen (Populus tremuloides Michx.), as well as a slight positive phenotypic correlation between fiber length and growth rate. In addition, large differences in mechanical and chemical properties of wood among different poplar varieties and clones have been reported by Wang et al. (2001), resulting in the selection of the best varieties and clones for use in the short-period timber industry.

The above studies demonstrated the existence of significant differences in anatomical, physical, mechanical and chemical properties of poplar wood among species and clones. However, a few studies are currently available in the literature on wood variability of $P$. ussuriensis, in particular on wood properties such as microfibril angle, cell wall percentage, fiber double wall thickness and tissue proportion.

Selection is a powerful tool for genetic improvement of forest trees and the selection method has a relevant effect on genotype improvement. One of the major difficulties faced by tree breeders is the negative correlation between wood properties and growth traits when selecting promising genotypes (Missanjo \& Matsumura 2017). The selection index is one of the helpful tools in the selection process, as it allows for multiple traits of interest to be selected simultaneously (Vieira et al. 2016). Missanjo \& Matsumura (2017) used a multiple trait selection index to select superior trees of Khasi pine (Pinus kesiya Royle ex Gordon).

In this study, clones were collected from the Chinese range of $P$. ussuriensis and planted at the Maoershan Experimental Forest Farm of Northeast Forestry University (Heilongjiang, China - Fig. 1). Ten years after planting, the growth traits and wood properties of each clone were determined. The goals were to evaluate variation patterns in growth traits and wood properties of different $P$. ussuriensis clones and preliminary selection of fast-growing, highquality clones for pulpwood.

\section{Materials and methods}

\section{Materials}

The materials used in this study were 45 P. ussuriensis clones (Tab. 1). In the winter of 2001-2002, cuttings were collected from excellent trees within the Chinese distribution range of $P$. ussuriensis. In 2003, cuttings were propagated in the nursery and then planted the field in 2007 at an experimental forest site in Maoershan, Shangzhi City, Heilongjiang Province (North-East China). The trial was conducted under a randomized complete block design consisting of three blocks, with 45 clones in every block; 15 trees of each clone were planted in one block, spaced at $2 \times 2 \mathrm{~m}$. Unfortunately, some trees died due to pests and diseases. 
Determination of growth traits

During the autumn of 2015 (10 years after planting), tree height $(\mathrm{H})$ and diameter at breast height $(\mathrm{DBH})$ of all trees were measured. The stem volume $(\mathrm{V})$ of each tree was calculated based on DBH $\left(D_{1.3}\right)$ and $H$, as described by Li \& Li (2014 - eqn. 1):

$V=0.000041960698 \cdot D_{1.3}^{1.9094595} \cdot H^{1.0413892}$

(1)

\section{Determination of wood properties}

Wood cores were taken at DBH along the north-south direction from three ramets per clone in every block, and used for the assessment of subsequent wood properties.

The basic wood density (BWD) was measured using the saturated water method (Yu et al. 2014).

The fiber lengths and widths were measured by the Jeffrey method (Prasad \& AlSagheer 2012), with all materials soaking in a mixture of $10 \%$ nitric acid and $10 \%$ chromic acid for 4 hours. Materials were rinsed with deionized water several times until the solution was neutral. Samples were measured under a Zeiss ${ }^{T M}$ optical microscope, and 50 fibers were measured for each sample.

Microfibril angles (MA) were determined by the iodine staining method (Cui et al. 1999). The wood cores were sliced in the middle of the annual rings near the bark, with a thickness of approximately 15-19 $\mu \mathrm{m}$ per slice. Angles were observed under a 400-fold readable angle microscope, and 20 microfibril angles were measured for each sample.

Measurements of cell wall percentage (CWP), fiber double wall thickness (FWT) and tissue proportion were also taken. Softened wood samples were sliced using a slippery wood slicer, with slices taken at a thickness of 12-16 $\mu \mathrm{m}$. After dyeing, dehydration by ethanol and clearing by xylene, a Nikon ${ }^{\text {TM }} 8 \mathrm{oi}^{\oplus}$ microscope and a DS-Ri1 ${ }^{\oplus}$ digital camera (Nikon Imaging Inc., Tokyo, Japan) were used to collect clear wood photos in the middle of the two rounds near the bark according to measurement requirements (Zheng et al. 2017). TDY-5.2 color image computer analysis software was used for image analysis.

Holocellulose content ( $\mathrm{HC}$ ) was measured using an ANKOM 2000i ${ }^{\oplus}$ automated fiber analyzer (ANKOM Technology, Macedon, NY, USA).

\section{Statistical analysis}

Analysis of variance (ANOVA) was performed using the statistical package SPSS ${ }^{\circledR}$ ver. 22.0 (IBM, Armonk, NY, USA). The following linear models were used (eqn. 2):

$$
Y_{i j}=\mu+P_{i}+B_{j}+\varepsilon_{i j}
$$

where $Y_{i j}$ is the observations, $\mu$ is the mean, $P_{\mathrm{i}}$ is the clone effect, $B_{\mathrm{j}}$ is the block effect, and $\varepsilon_{i j}$ is the random error.

The genotypic $\left(\sigma_{\mathrm{g}}^{2}\right)$ and phenotypic $\left(\sigma_{\mathrm{p}}^{2}\right)$ variances were calculated using the mean squares from ANOVA as described by Metougui et al. (2017 - eqn. 3, eqn. 4):

$$
\begin{aligned}
& \sigma_{g}^{2}=(A-B) / r \\
& \sigma_{p}^{2}=\sigma_{g}^{2}+\sigma_{\varepsilon}^{2}
\end{aligned}
$$

where $A=\sigma_{\varepsilon}^{2}+r \sigma_{g}^{2}$ is the mean square between clones, $B=\sigma_{\varepsilon}^{2}$, is the mean square within families, and $r$ is the number of replications.

The phenotypic coefficient of variation $(\mathrm{PCV}, \%)$ and the genotypic coefficient of variation (GCV, \%) were estimated as follows (Jonah 2011 - eqn. 5, eqn. 6):

$$
\begin{aligned}
& P C V=\sqrt{\frac{\sigma_{p}^{2}}{\bar{X}} \cdot 100} \\
& G C V=\sqrt{\frac{\sigma_{g}^{2}}{\bar{X}} \cdot 100}
\end{aligned}
$$

\section{Results}

(6) Survival rates of clones

The average survival rate of the $45 \mathrm{P}$. us where $\bar{X}$ is the mean value of a single trait among all clones. Broad-sense heritability $\left(H^{2}\right)$ for the clones was calculated using the following equation (Xu 2006 - eqn. 7):

$$
H^{2}=1-\frac{1}{F}
$$

where $F$ is the F-value from the ANOVA table.

The genetic correlation coefficient was calculated as (Becker 1985 - eqn. 8):

$$
r_{g(x y)}=\frac{\sigma_{g(x y)}}{\sqrt{\sigma_{g(x)}^{2} \sigma_{g(y)}^{2}}}
$$

where $\sigma_{g(x y)}^{2}$ is the genetic covariance of trait $x$ and trait $y, \sigma_{g(x)}^{2}$ is the genetic variance of trait $x$, and $\sigma_{g(y)}^{2}$ is the genetic variance of trait $y$.

The selection index was obtained using the software package DPS ver. 16.05 (DPS

Tab. 2 - Variation and genetic parameters of growth traits and wood properties. $(H)$ : tree height, $\mathrm{m}$; $(\mathrm{DBH})$ : diameter at breast height, $\mathrm{cm}$; $(\mathrm{V})$ : volume, $\mathrm{m}^{3}$; (BWD): basic wood density, $\mathrm{g} / \mathrm{cm}^{3}$; (FL): fiber length, $\mu \mathrm{m}$; (FL/W): fiber length-width ratio; (MA): microfibril angle, ${ }^{\circ}$; (CWP): cell wall percentage, \%; (FWT): fiber double wall thickness, $\mu \mathrm{m}$; (VP): vessel proportion, \%; (FP): wood fiber proportion, \%; (RP): wood ray propor tion, \%; (HC): holocellulose content, \%; (PCV): phenotypic coefficient of variation, \%; (GCV): genotypic coefficient of variation, \%.

\begin{tabular}{|lccrrrrr}
\hline Traits & Average & Range & PCV & \multicolumn{1}{c}{ GCV } & \multicolumn{1}{c}{$H^{2}$} & $\sigma_{\mathrm{g}}^{2}$ & \multicolumn{1}{c}{$\sigma_{\mathrm{p}}^{2}$} \\
\hline H & 10.34 & $7.77-12.44$ & 15.68 & 2.70 & 0.084 & 0.08 & 2.63 \\
\hline DBH & 9.32 & $6.58-10.76$ & 12.83 & 8.07 & 0.663 & 0.57 & 1.43 \\
\hline V & 0.0375 & $0.0175-0.0537$ & 31.55 & 14.61 & 0.477 & 0.00003 & 0.0001 \\
\hline BWD & 0.2705 & $0.2421-0.3083$ & 7.39 & 5.23 & 0.749 & 0.0002 & 0.0004 \\
\hline FL & 767.65 & $677.01-855.56$ & 9.21 & 2.75 & 0.227 & 445.78 & 4998.28 \\
\hline FL/W & 29.52 & $26.96-35.04$ & 8.33 & 2.71 & 0.263 & 0.64 & 6.68 \\
\hline MA & 12.63 & $9.30-18.67$ & 20.49 & 7.30 & 0.302 & 0.85 & 6.70 \\
\hline CWP & 38.00 & $32.13-46.87$ & 13.00 & 4.83 & 0.325 & 3.37 & 24.39 \\
\hline FWT & 3.96 & $3.39-5.06$ & 12.88 & 7.14 & 0.557 & 0.08 & 0.26 \\
\hline VP & 25.99 & $20.35-32.38$ & 14.28 & 8.31 & 0.606 & 4.66 & 13.77 \\
\hline FP & 69.57 & $63.57-75.45$ & 5.21 & 3.06 & 0.614 & 4.54 & 13.12 \\
\hline RP & 4.45 & $3.45-5.45$ & 17.26 & 5.02 & 0.220 & 0.05 & 0.59 \\
\hline HC & 75.46 & $70.05-80.11$ & 3.29 & 1.07 & 0.261 & 0.65 & 6.18 \\
\hline
\end{tabular}


Tab. 3 - Results of the ANOVA on growth traits and wood properties. $(\mathrm{H})$ : tree height; (DBH): diameter at breast height; (V): volume; (BWD): basic wood density; (FL): fiber length; (FL/W): fiber length-width ratio; (MA): microfibril angle; (CWP): cell wall percentage; (FWT): fiber double wall thickness; (VP): vessel proportion; (FP): wood fiber proportion; (RP): wood ray proportion; (HC): holocellulose content; (SV): sources of variation; $(*): p<0.05 ;(* *): p<0.01$.

\begin{tabular}{|c|c|c|c|c|}
\hline Variable & SV & $d f$ & MS & $F$ \\
\hline \multirow[t]{3}{*}{$\mathrm{H}$} & Clone & 44 & 2.787 & 1.092 \\
\hline & Block & 2 & 36.398 & $14.260^{* *}$ \\
\hline & Error & 88 & 2.552 & - \\
\hline \multirow[t]{3}{*}{ DBH } & Clone & 44 & 2.559 & $2.967^{* *}$ \\
\hline & Block & 2 & 30.688 & $35.577^{* *}$ \\
\hline & Error & 88 & 0.863 & - \\
\hline \multirow[t]{3}{*}{ V } & Clone & 44 & 0.000 & $1.912^{* *}$ \\
\hline & Block & 2 & 0.003 & $27.276^{* *}$ \\
\hline & Error & 88 & 0.000 & - \\
\hline \multirow[t]{3}{*}{ BWD } & Clone & 44 & 0.001 & $3.984^{* *}$ \\
\hline & Block & 2 & 0.003 & $12.307^{* *}$ \\
\hline & Error & 88 & 0.000 & - \\
\hline \multirow[t]{3}{*}{$\mathrm{FL}$} & Clone & 44 & 5889.838 & 1.294 \\
\hline & Block & 2 & 52237.796 & $11.475^{* *}$ \\
\hline & Error & 88 & 4552.502 & - \\
\hline \multirow[t]{3}{*}{$\mathrm{FL} / \mathrm{W}$} & Clone & 44 & 7.319 & 1.357 \\
\hline & Block & 2 & 63.509 & $11.774^{* *}$ \\
\hline & Error & 88 & 5.394 & - \\
\hline \multirow[t]{3}{*}{ MA } & Clone & 44 & 8.387 & 1.433 \\
\hline & Block & 2 & 5.084 & 0.869 \\
\hline & Error & 88 & 5.851 & - \\
\hline \multirow[t]{3}{*}{ CWP } & Clone & 44 & 31.139 & 1.482 \\
\hline & Block & 2 & 293.697 & $13.976^{* *}$ \\
\hline & Error & 88 & 21.015 & - \\
\hline \multirow[t]{3}{*}{ FWT } & Clone & 44 & 0.409 & $2.255^{* *}$ \\
\hline & Block & 2 & 7.053 & $38.886^{* *}$ \\
\hline & Error & 88 & 0.181 & - \\
\hline \multirow[t]{3}{*}{ VP } & Clone & 44 & 23.103 & $2.535^{* *}$ \\
\hline & Block & 2 & 74.965 & $8.227^{* *}$ \\
\hline & Error & 88 & 9.112 & - \\
\hline \multirow[t]{3}{*}{ FP } & Clone & 44 & 22.204 & $2.588^{* *}$ \\
\hline & Block & 2 & 27.390 & $3.193^{*}$ \\
\hline & Error & 88 & 8.579 & - \\
\hline \multirow[t]{3}{*}{$\mathrm{RP}$} & Clone & 44 & 0.689 & 1.282 \\
\hline & Block & 2 & 15.135 & $28.184^{* *}$ \\
\hline & Error & 88 & 0.537 & - \\
\hline \multirow[t]{3}{*}{$\mathrm{HC}$} & Clone & 44 & 7.487 & 1.354 \\
\hline & Block & 2 & 0.315 & 0.057 \\
\hline & Error & 88 & 5.531 & - \\
\hline
\end{tabular}

$2.70 \%$ to $14.61 \%$, respectively. $H^{2}$ of growth traits varied from 0.084 to 0.663 .

Total average BWD was $0.2705 \mathrm{~g} \mathrm{~cm}^{-3}$, with the biggest clone $M 17\left(0.3083 \mathrm{~g} \mathrm{~cm}^{-3}\right)$ bigger than the smallest clone D16 (0.2421 $\mathrm{g} \mathrm{cm}^{-3}$ ) by $27 \%$. Total average FL was 767.65 $\mu \mathrm{m}$, with the longest clone $\mathrm{C}_{14}(677.01 \mu \mathrm{m})$ longer than the smallest clone I18 (855.56 $\mu \mathrm{m})$ by $26 \%$. Total average FL/W, CWP and FWT were $29.52,38.00 \%$ and $3.96 \mu \mathrm{m}$, respectively. The highest average $\mathrm{FL} / \mathrm{W}$ (35.04), CWP (46.87\%) and FWT $(5.06 \mu \mathrm{m})$ were observed for clone $\mathrm{J} 19$ and were higher than the lowest average FL/W, CWP and FWT in clone C14 (26.96), M14 (32.13\%) and $\mathrm{D} 13(3.39 \mu \mathrm{m})$ by $30 \%, 46 \%$ and $49 \%$, re- respectively. $\mathrm{H}^{2}$ of wood properties varied from 0.220 to 0.749 . BWD, FWT, VP and FP showed moderate genetic control, while all of the wood properties were genetically controlled to at least a mild degree.

\section{ANOVA for growth traits and wood properties}

The ANOVA results for growth traits and wood properties for 10-year-old clones of $P$. ussuriensis are shown in Tab. 3. The results showed significant $(P<0.05)$ differences in DBH, V, BWD, FWT, VP and FP among clones. In addition, there were significant $(P<0.05)$ differences for all growth traits and wood properties among blocks, except for the MA and $\mathrm{HC}$ traits.

\section{Relationships among traits}

The relationships among traits are shown in Tab. 4. Both $\mathrm{H}$ and DBH showed significant positive correlations $(P<0.01)$ with $\mathrm{V}$. The phenotypic and genetic correlation coefficients were 0.887 and 0.990 for $\mathrm{H}$ and 0.900 and 0.980 for $\mathrm{DBH}$, respectively. $\mathrm{H}$ had a significant positive correlation $(P$ $<0.01)$ with $\mathrm{DBH}$, with a phenotypic and genetic correlation coefficient of 0.690 and 0.990, respectively.

BWD had a significant positive correlation $(P<0.05)$ with $\mathrm{FL} / \mathrm{W}$ and a significant negative correlation $(P<0.01)$ with FL. The phenotypic correlation coefficients (the corresponding genetic correlation coefficients are reported in brackets henceforth) were 0.117 (0.789) and -0.221 (0.135) for FL/W and FL respectively. FL had a significant positive correlation $(P<0.01)$ with $\mathrm{FL} / \mathrm{W}, \mathrm{FWT}$ and RP and a significant negative correlation $(P<0.05)$ with VP. The phenotypic (genetic) correlation coefficients were 0.621 (0.113), 0.302 (0.314), $0.281(-0.140)$ and $-0.211(-0.574)$ for these traits, respectively. FL/W had significant positive correlations $(P<0.01)$ with CWP, FWT and RP. The phenotypic (genetic) correlation coefficients were 0.331 (0.998), 0.393 (0.970) and 0.313 (0.233) for these traits, respectively. CWP had significant positive correlations $(P<0.01)$ with FWT and RP. The phenotypic (genetic) correlation coefficients were $0.787(0.970)$ and $0.362(-0.118)$ for FWT and $R P$, respectively. FWT showed a significant positive correlation $(P<0.01)$ with RP. The phenotypic (genetic) correlation coefficient was $0.412(-0.042)$. VP had significant negative correlations $(P<0.01)$ with FP and RP. The phenotypic (genetic) correlation coefficients were $-0.972(-0.995)$ and $-0.314(-0.175)$ for these traits, respectively.

DBH had a significant negative correlation $(P<0.05)$ with VP and a significant positive correlation $(P<0.05)$ with FP. The phenotypic (genetic) correlation coefficients were $-0.219(-0.121)$ and 0.190 (0.164) for these traits, respectively. BWD had significant negative correlations $(P<0.01)$ with $\mathrm{H}$, $\mathrm{DBH}$ and $\mathrm{V}$. There were negative correlations between growth traits and BWD. The phenotypic (genetic) correlation coefficients were $-0.375(-0.987),-0.505(-0.670)$ 
Tab. 4 - Correlation coefficients of different traits. The phenotypic correlation coefficient are shown above the diagonal (upper right part), while the genetic correlation coefficient are reported below the diagonal (lower left part). (H): tree height; (DBH): diameter at breast height; (V): volume; (BWD): basic wood density; (FL): fiber length; (FL/W): fiber length/width; (MA): microfibril angle; (CWP): cell wall percentage; (FWT): fiber double wall thickness; (VP): vessel proportion; (FP): wood fiber proportion; (RP): wood ray proportion; (HC): holocellulose content; $(*): p<0.05 ;(* *): p<0.01$.

\begin{tabular}{llllllllllllll}
\hline- & H & DBH & V & BWD & FL & FL/W & MA & CWP & FWT & VP & FP & RP & HC \\
\hline H & 1 & $0.690^{* *}$ & $0.887^{* *}$ & $-0.375^{* *}$ & $0.169^{*}$ & -0.099 & -0.050 & -0.043 & 0.133 & 0.064 & -0.085 & 0.072 & 0.050 \\
DBH & 0.990 & 1 & $0.900^{* *}$ & $-0.505^{* *}$ & $0.361^{* *}$ & -0.045 & 0.009 & -0.117 & 0.103 & $-0.219^{*}$ & $0.190^{*}$ & 0.165 & 0.087 \\
V & 0.990 & 0.980 & 1 & $-0.474^{* *}$ & $0.328^{* *}$ & -0.065 & 0.009 & -0.085 & 0.121 & -0.139 & 0.108 & 0.157 & 0.113 \\
BWD & $-0.987^{*}$ & -0.670 & -0.400 & 1 & $-0.221^{* *}$ & $0.177^{*}$ & 0.051 & 0.162 & 0.004 & -0.023 & 0.024 & -0.001 & -0.062 \\
FL & 0.980 & 0.828 & 0.980 & 0.135 & 1 & $0.621^{* *}$ & -0.064 & 0.066 & $0.302^{* *}$ & $-0.211^{*}$ & 0.152 & $0.281^{* *}$ & 0.061 \\
FL/W & -0.203 & -0.338 & -0.166 & 0.789 & 0.113 & 1 & -0.067 & $0.331^{* *}$ & $0.393^{* *}$ & -0.117 & 0.046 & $0.313^{* *}$ & -0.051 \\
MA & 0.035 & 0.068 & 0.100 & 0.265 & -0.047 & 0.393 & 1 & -0.025 & -0.086 & -0.129 & 0.127 & 0.034 & -0.141 \\
CWP & -0.999 & -0.572 & -0.857 & 0.503 & -0.280 & 0.998 & 0.461 & 1 & $0.787^{* *}$ & 0.030 & -0.120 & $0.362^{* *}$ & -0.097 \\
FWT & -0.995 & -0.435 & -0.658 & 0.352 & 0.314 & 0.970 & 0.174 & 0.970 & 1 & -0.106 & 0.010 & $0.412^{* *}$ & 0.033 \\
VP & 0.999 & -0.121 & -0.104 & -0.107 & -0.574 & -0.171 & $-0.945^{*}$ & -0.035 & 0.088 & 1 & $-0.972^{* *}$ & $-0.314^{* *}$ & -0.109 \\
FP & $-0.940^{*}$ & 0.164 & 0.153 & 0.054 & 0.597 & 0.233 & $0.892^{*}$ & 0.047 & -0.085 & $-0.995^{* *}$ & 1 & 0.084 & 0.115 \\
RP & -0.625 & -0.388 & -0.437 & 0.517 & -0.140 & -0.574 & 0.625 & -0.118 & -0.042 & -0.175 & -0.241 & 1 & -0.004 \\
HC & 0.468 & 0.091 & 0.379 & 0.414 & 0.990 & 0.865 & 0.150 & 0.990 & 0.640 & 0.398 & -0.241 & -0.241 & 1 \\
\hline
\end{tabular}

and $-0.474(-0.400)$ for these traits, respectively. FL had a significant positive correlation $(P<0.05)$ with $\mathrm{H}$. In addition, $\mathrm{FL}$ had significant positive correlations $(P<0.01)$ with $\mathrm{DBH}$ and $\mathrm{V}$. The phenotypic (genetic) correlation coefficients were $0.169(0.980)$, $0.361(0.828)$ and $0.328(0.980)$ for these traits, respectively.

Generally, FL and growth traits showed significant positive correlations, while BWD and growth traits showed significant negative correlations. Neither MA nor $\mathrm{HC}$ had a significant correlation with other traits. Thus, MA and $\mathrm{HC}$ can be independently selected.

\section{Multitrait index selection}

The multi-trait selection index is a comprehensive index based on heritability and genotypic and phenotypic trait correlations which combines multiple target traits to obtain the greatest improvement. Accord- ing to the ANOVA results, DBH, V, BWD, FWT, VP and FP (six traits in total) were significantly different among clones. Since MA and FL are usually used for the purpose of breeding, these and five other traits were selected as quantitative traits for further analyses. Eight traits (DBH, V, BWD, FL, MA, FWT, VP, FP) were used to build the index selection equation for comprehensive selection of growth traits and wood properties. Economic weight was estimated by the equal weight method; that is, the reciprocal of the standard deviation of each trait phenotype was used as the weight of the trait. These included $\mathrm{DBH}$ $\left(x_{1}\right), V\left(x_{2}\right)$, BWD $\left(x_{3}\right)$, FL $\left(x_{4}\right)$, MA $\left(x_{5}\right)$, FWT $\left(\mathrm{x}_{6}\right)$, VP $\left(\mathrm{x}_{7}\right)$ and FP $\left(\mathrm{x}_{8}\right)$. Economic weight vectors $(\mathrm{W})$ were $0.7323,74.1374,47.6404$, $0.0132,-0.3871,1.6698,-0.2609$ and 0.2739 for these traits, respectively. To reduce potential negative effects of traits in the exponential equation, the Kempthorne con- straint index method was used to constrain the genetic progress of MA and VP to zero in order to maximize the genetic gain of the other traits.

The restricted and unrestricted selection index equations and the selection progress of trait breeding and are shown in Tab. 5 . The partial regression coefficients of FWT and FP in equations $I_{1}, I_{2}, I_{3}, I_{4}, I_{9}, I_{10}, l_{11}$ and $I_{12}$ were negative, and the partial regression coefficients of MA and VP in equations $I_{5}$, $\mathrm{I}_{6}, \mathrm{I}_{7}$ and $\mathrm{I}_{8}$ were negative, so these equations were not ideal. The selection progress and partial regression coefficients of all traits (including $\mathrm{DBH}, \mathrm{BWD}$ and $\mathrm{FL}$, but not MA) were positive in equation $I_{14}$. The selection progress of comprehensive breeding was 0.8641 , the estimated accuracy of comprehensive breeding was 0.7200 , index heritability was 0.5520 and the selection progress of $\mathrm{DBH}, \mathrm{BWD}, \mathrm{FL}$ and MA was $0.4517,0.0030,29.6198$ and

Tab. 5 - The restricted and unrestricted selection index equations and the selection progress of trait breeding. (SP): the selection progress of comprehensive breeding; (Acc): estimated accuracy of comprehensive breeding; (Hi): heritability index. For a full description of predictor traits $\left(x_{1}, \ldots, x_{8}\right)$, see the text.

\begin{tabular}{lllll}
\hline Kind & Selection index equations & SP & Acc & Hi \\
\hline Unrestricted & $\mathrm{I}_{1}=0.3802 \mathrm{x}_{1}+30.9886 \mathrm{x}_{2}+50.7049 \mathrm{x}_{3}+0.0204 \mathrm{x}_{4}+0.2625 \mathrm{x}_{5}-0.3042 \mathrm{x}_{6}+0.6773 \mathrm{x}_{7}+0.8956 \mathrm{x}_{8}$ & 2.2270 & 0.9537 & 0.7730 \\
& $\mathrm{I}_{2}=0.5192 \mathrm{x}_{1}+17.9449 \mathrm{x}_{2}+47.8234 \mathrm{x}_{3}+0.0165 \mathrm{x}_{4}+0.1301 \mathrm{x}_{5}-0.5377 \mathrm{x}_{6}-0.0213 \mathrm{x}_{7}$ & 1.6626 & 0.8769 & 0.7093 \\
\cline { 2 - 6 } & $\mathrm{I}_{3}=0.5657 \mathrm{x}_{1}+4.5943 \mathrm{x}_{2}+26.5315 \mathrm{x}_{3}+0.1085 \mathrm{x}_{5}-0.0582 \mathrm{x}_{6}+0.0561 \mathrm{x}_{8}$ & 0.8634 & 0.7366 & 0.6125 \\
\cline { 2 - 6 } & $\mathrm{I}_{4}=0.4813 \mathrm{x}_{1}+19.4210 \mathrm{x}_{2}+41.4966 \mathrm{x}_{3}+0.0130 \mathrm{x}_{4}-0.0228 \mathrm{x}_{5}-0.3527 \mathrm{x}_{6}$ & 1.3683 & 0.7812 & 0.6985 \\
\cline { 2 - 6 } & $\mathrm{I}_{5}=0.3272 \mathrm{x}_{1}+57.6935 \mathrm{x}_{2}+37.1581 \mathrm{x}_{3}+0.0116 \mathrm{x}_{4}+0.0873 \mathrm{x}_{5}+0.0893 \mathrm{x}_{8}$ & 1.6657 & 0.8349 & 0.7326 \\
\cline { 2 - 6 } Restricted & $\mathrm{I}_{6}=57.1845 \mathrm{x}_{2}+48.1969 \mathrm{x}_{3}+0.0101 \mathrm{x}_{4}+0.0701 \mathrm{x}_{5}+0.0889 \mathrm{x}_{8}$ & 1.3447 & 0.8920 & 0.8820 \\
& $\mathrm{I}_{7}=0.6471 \mathrm{x}_{1}+29.2781 \mathrm{x}_{2}+53.9793 \mathrm{x}_{3}+0.0065 \mathrm{x}_{4}+0.0216 \mathrm{x}_{5}+0.6907 \mathrm{x}_{6}+0.5655 \mathrm{x}_{7}+0.4685 \mathrm{x}_{8}$ & 1.3860 & 0.5935 & 0.6467 \\
& $\mathrm{I}_{8}=0.6471 \mathrm{x}_{1}+23.5232 \mathrm{x}_{2}+52.7317 \mathrm{x}_{3}+0.0073 \mathrm{x}_{4}+0.0184 \mathrm{x}_{5}+0.3134 \mathrm{x}_{6}+0.1248 \mathrm{x}_{7}$ & 1.3317 & 0.7023 & 0.6368 \\
\cline { 2 - 6 } & $\mathrm{I}_{9}=0.6807 \mathrm{x}_{1}-8.3991 \mathrm{x}_{2}+20.5807 \mathrm{x}_{3}+0.0017 \mathrm{x}_{5}-0.2080 \mathrm{x}_{6}-0.0485 \mathrm{x}_{8}$ & 0.6885 & 0.5874 & 0.5572 \\
\cline { 2 - 6 } & $\mathrm{I}_{10}=0.4505 \mathrm{x}_{1}+16.3953 \mathrm{x}_{2}+35.5167 \mathrm{x}_{3}+0.0132 \mathrm{x}_{4}-0.1088 \mathrm{x}_{5}-0.4656 \mathrm{x}_{6}$ & 1.3436 & 0.7671 & 0.6479 \\
\cline { 2 - 6 } & $\mathrm{I}_{11}=0.4656 \mathrm{x}_{1}+39.3867 \mathrm{x}_{2}+29.1130 \mathrm{x}_{3}+0.0123 \mathrm{x}_{4}-0.0454 \mathrm{x}_{5}-0.0478 \mathrm{x}_{8}$ & 1.5264 & 0.7651 & 0.6084 \\
\cline { 2 - 6 } & $\mathrm{I}_{12}=49.7285 \mathrm{x}_{2}+38.9926 \mathrm{x}_{3}+0.0109 \mathrm{x}_{4}-0.0651 \mathrm{x}_{5}-0.0457 \mathrm{x}_{8}$ & 1.1636 & 0.7719 & 0.7008 \\
\cline { 2 - 6 } & $\mathrm{I}_{13}=0.1775 \mathrm{x}_{1}+29.4083 \mathrm{x}_{3}+0.0091 \mathrm{x}_{4}-0.1150 \mathrm{x}_{5}+0.3890 \mathrm{x}_{6}$ & 0.9723 & 0.6907 & 0.5230 \\
\cline { 2 - 5 } & $\mathrm{I}_{14}=0.4318 \mathrm{x}_{1}+27.5706 \mathrm{x}_{3}+0.0067 \mathrm{x}_{4}-0.1041 \mathrm{x}_{5}$ & 0.8641 & 0.7200 & 0.5520 \\
\hline
\end{tabular}


Tab. 6 - Comprehensive evaluation of clones. (I): Selection index value.

\begin{tabular}{|llllll|}
\hline Clone & I & Clone & I & Clone & I \\
\hline J19 & 16.75 & H7 & 15.51 & B5 & 15.08 \\
\hline I18 & 16.29 & M19 & 15.50 & H4 & 15.08 \\
\hline H16 & 16.24 & M14 & 15.47 & D13 & 15.02 \\
\hline C13 & 16.14 & M10 & 15.46 & B8 & 14.94 \\
\hline D23 & 16.10 & I5 & 15.43 & D11 & 14.90 \\
\hline E9 & 15.92 & I10 & 15.40 & D22 & 14.82 \\
\hline C9 & 15.89 & M20 & 15.32 & H8 & 14.80 \\
\hline H13 & 15.89 & D16 & 15.26 & M16 & 14.77 \\
\hline I8 & 15.87 & M15 & 15.24 & B6 & 14.75 \\
\hline C16 & 15.86 & D17 & 15.19 & D5 & 14.49 \\
\hline C12 & 15.82 & J20 & 15.17 & F6 & 14.44 \\
\hline E8 & 15.81 & M13 & 15.13 & H12 & 14.39 \\
\hline D24 & 15.79 & C15 & 15.11 & C14 & 14.34 \\
\hline C1 & 15.70 & H5 & 15.10 & J9 & 14.27 \\
\hline M17 & 15.60 & D9 & 15.09 & E5 & 13.89 \\
\hline
\end{tabular}

0.0000 , respectively. Therefore, equation $\mathrm{I}_{14}$ was the best. According to the selection index equation, calculations of the index value of each clone are shown in Tab. 6 .

Outstanding clone selectivity was $10 \%$, selected from the top four excellent clones (J19, I18, H16, C13). DBH, V, BWD, FL, MA, FWT, VP and FP of excellent clones were higher than all clones by $7.29 \%, 13.92 \%$, $4.37 \%, 7.36 \%,-3.51 \%, 6.73 \%,-6.54 \%$ and $2.14 \%$, respectively.

\section{Discussion}

\section{Variation and heritability}

Numerous studies reported a wide range of genetic variation in growth and wood traits at the clonal level for forest tree species (Beaudoin et al. 1992, Prasad \& AlSagheer 2012). In this study, we found significant differences $(P<0.05)$ in $D B H, V$, BWD, FWT, VP and FP among 45 clones of Pinus ussuriensis. This indicates that clonal effects in the joint analysis for growth traits and wood properties were significant.

Mean values for $\mathrm{H}, \mathrm{DBH}$ and $\mathrm{V}$ of all clones ranged from $7.77 \mathrm{~m}$ to $12.44 \mathrm{~m}, 6.58$ $\mathrm{cm}$ to $10.76 \mathrm{~cm}$ and $0.0175 \mathrm{~m}^{3}$ to $0.0537 \mathrm{~m}^{3}$, respectively. The GCVs of growth traits of all clones ranged from $2.70 \%$ to $14.61 \%$. Among them, $V$ had the largest GCV. Higher GCV means that clones showed a greater potential for improving traits. $\mathrm{H}^{2}$ of growth traits ranged from 0.084 to 0.663 . This indicated that $\mathrm{V}$ and $\mathrm{DBH}$ were under moderate genetic control, while $\mathrm{H}$ was genetically controlled to only a mild degree.

The BWD mean values ranged from $0.2421 \mathrm{~g} \mathrm{~cm}^{-3}$ to $0.3083 \mathrm{~g} \mathrm{~cm}^{-3}$, smaller compared to previous studies of Populus tremuloides (Yanchuk et al. 1984) and Populus tremula (Kärki 2001) clones. The broadsense heritability of BWD was 0.499, higher than in previous studies (Zhang et al. 1996). These differences might be due to different sampling methods, including different sampling heights and different cambial age of samples. FL mean values ranged from $677.01 \mu \mathrm{m}$ to $855.56 \mu \mathrm{m}$, longer than those of $P$. ussuriensis (Zhang et al. 1996) and Populus balsamifera L. (Ivkovich 1996) clones previously studied. The mean FL/W ranged from 26.96 to 35.04. The mean MA ranged from $9.30^{\circ}$ to $18.67^{\circ}$. Density was generally considered one of the most important factors affecting wood properties such as stiffness, strength and shrinkage behavior (Evans \& Ilic 2001). However, it has been shown and theoretically (Cave 1976) that MA is at least as important as density for the prediction of strength and stiffness of solid wood. The results of this study showed smaller MA values than those reported for Betula pendula Roth (Bonham \& Barnett 2001). Decreased MA increases stiffness of cell walls (Cave 1968). The mean CWP range was 32.13 to 46.87 , similar to that reported in previous studies on poplars. Mean FWT ranged from $3.39 \mu \mathrm{m}$ to 5.06 $\mu \mathrm{m}$. In general, cell wall thickness is related to wood hardness, with greater thickness of the cell wall leading to greater hardness of wood. Mean VP, FP and RP ranged from $20.35 \%$ to $32.38 \%, 63.57 \%$ to $75.45 \%$ and $3.45 \%$ to $5.45 \%$, respectively. Angiosperm wood consists mainly of axially elongated vessel elements and fibers, with radially elongated ray cells (Mellerowicz et al. 2001). Tissue proportion of different wood elements showed that wood fiber proportion is at maximum. Compared with the genus Quercus (Sharma et al. 2011), the results of this study showed a higher fiber proportion and lower wood ray proportion. Mean $\mathrm{HC}$ ranged from $70.05 \%$ to $80.11 \%$. HC showed a significant effect on the nature and utilization of the wood. The result was similar to previous studies of Populus deltoides Bartr. (Klasnja et al. 2003). From the perspective of PCVs, HC had the smallest and MA the largest values, while as for GCVs, HC had the smallest and VP the largest values. Broad-sense herboth experimentally (Cave \& Walker 1994) itabilities ranged from 0.220 to 0.749 , i.e., moderate to low values for wood properties. This is similar to previous studies by Atwood et al. (2002) and Doran et al. (2012). Combined with a modest coefficient of variation, genetic improvement through recurrent selection and breeding is promising.

Populus species are present across a broad range of climatic and edaphic conditions, bearing an important ecophysiological variability that often underlies inter and intraspecific adaptation patterns (Dickmann 2001). Zhang et al. (2015) have proven $P$. ussuriensis not only adapts to flat land and river beach but also to hillside land, with no disease or frost damage, thus having great growth potential (Zhang et al. 2015).

\section{Relationship between growth traits and} wood properties

Sampling of wood properties is not only destructive and costly but also complicated. If the correlations among traits are already known, money and time can be saved by predicting or indirectly selecting unknown traits using known traits. Knowledge of the phenotypic and genotypic relationships between growth traits and wood properties is critical for their simultaneous genetic improvement.

Growth traits were all highly positive correlated. Growth traits and BWD were extremely negatively correlated, similar to Picea abies (Hannrup 2009). This indicates the rapid growth rate was not conducive to the formation of large-density wood. There was significant positive correlation among $\mathrm{DBH}, \mathrm{FL}$ and $\mathrm{FP}$, which shows that diameter growth was beneficial to long fiber formation. In addition, DBH had significant negative correlation with VP, but the correlation coefficient was small. These results were similar to those found in Larix kaempferi (Nakada et al. 2005). Moreover, we found no significant correlations between growth traits and $\mathrm{FL} / \mathrm{W}, \mathrm{MA}, \mathrm{CWP}$, FWT, RP or HC, indicating that these traits were independently inherited and could potentially be selected independently. On the other hand, we found negative correlations between growth and wood traits (BWD, FL/W, MA, CWP, VP and FP), similar to what was previously reported in poplar (Hernández et al. 1998).

\section{Multi-trait index selection}

It is often difficult to comprehensively improve the yield and quality of trees due to negative correlations between growth and wood traits. The selection index is a helpful tool for guiding this process, allowing for multiple features of interest to be selected at one time (Missanjo \& Matsumura 2017). Christophe \& Birot (1983) and Nebgen \& Lowe (1985) used the multi-trait selection index to screen many provenances, clones and pedigrees for growth traits and wood properties.Guan et al. (2005) used the multi-trait selection index to select supe- 
rior clones of Populus deltoids $\times$ P. euramericana based on growth trait data, including wood properties and stem forms, of $3312-$ year-old $F_{1}$ clones. Aggregate character was improved with selection index, but the genetic gain of single characters using the selection index was lower than that obtainable from single-character selection. Zhou et al. (1994) suggests that when using a selection index for joint selection of growth and material properties, the number of traits considered in constructing the selection index equations should not be excessive. In this study, eight quantitative traits were selected as predictors according to the results of ANOVA, with correlations between traits and breeding objectives. The best equation was chosen according to breeding objectives, selection progress and estimated accuracy of comprehensive breeding. Based on the selection index equation and selectivity (10\%), the top four clones (J19, I18, H16, C13) resulted as superior clones. The averages of BWD, FL, FL/W, MA, CWP, FWT, VP, FP, RP and HC of these excellent clones were $0.2823 \mathrm{~g} \mathrm{~cm}^{-3}, 824.13$ $\mu \mathrm{m}, 31.04,12.18^{\circ}, 39.07 \%, 4.22 \mu \mathrm{m}, 24.29 \%$, $71.06 \%, 4.66 \%$, $75.44 \%$, respectively. The fiber length was $824.13 \mu \mathrm{m}$, meeting the slightly shorter fiber standard (700-900 $\mu \mathrm{m})$ specified by International Association of Wood Anatomists. The fiber length-width ratio satisfies the pulping performance standard $(>30)$. The microfibril angle is $12.18^{\circ}$, the fiber strength increases with the decrease of microfibril angle. The fiber ratio and the holocellulose content were greater than $70 \%$, which was suitable for pulp. Therefore, the selected clones can meet the requirements of the pulp and paper industry, being an excellent pulp material variety. Multi-trait index selection will be beneficial for future breeding programs, in particular when there is negative correlation between growth traits and wood properties.

\section{Conclusion}

This study assessed the genetic variation of growth traits and wood properties of 45 $P$. ussuriensis clones. Significant differences between clones for most growth traits and wood properties reflected the selective breeding value of clones. Analysis of broadsense heritability showed that growth traits and wood properties are genetically controlled only at moderate to low levels. We found negative correlations between growth traits and most wood properties. To improve growth and wood traits simultaneously, the multi-trait selection index method was used to pick out the excellent clones. Combined with the survival rates of clones, the three clones selected (I18, H16, C13) showed higher values than all other clones by $2.83 \%, 9.81 \%, 3.40 \%, 6.59 \%,-7.54 \%$, $-0.39 \%,-2.12 \%$ and $0.31 \%$ for diameter at breast height, volume, basic wood density, fiber length, microfibril angle, fiber double wall thickness, vessel proportion and wood fiber proportion measurements, respec- tively. The results demonstrated that this method is feasible, and combined selection for growth and wood properties is effective for tree improvement.

The conclusions of this study is based on a single site, but it could be used for the further studies on breeding and genetic improvement of $P$. ussuriensis. In addition, the study on microfibril angle, cell wall percentage, fiber double wall thickness and tissue proportion is conducive to the selection of high-quality pulpwood clones.

\section{Acknowledgements}

Jiaojiao Jin and Kailong Li conceived and designed the experiments. Jiaojiao Jin, Xiyang Zhao, Huanzhen Liu, Ziwen Song and Xuyu Ma performed the experiments. Kailong Li provided reagents, materials and tools and provided careful guidance. Jiaojiao Jin analyzed the data, summarized the results and wrote the manuscript. Kailong Li, Xiyang Zhao, Huanzhen Liu and Sui Wang revised the manuscript.

This work was supported by the National Key R \& D Program of China (Grant No. 2016YFD0600404).

\section{References}

Atwood R, White T, Huber D (2002). Genetic parameters and gains for growth and wood properties in Florida source loblolly pine in the southeastern United States. Canadian Journal of Forest Research 32 (6): 1025-1038. - doi: 10.1139/x02-025

Beaudoin M, Hernández RE, Koubaa A, Poliquin J (1992). Interclonal, intraclonal and within-tree variation in wood density of poplar hybrid clones. Wood and Fiber Science 24 (2): 147-153. [online] URL: http://wfs.swst.org/index.php/wf s/article/view/1864

Becker WA (1985). Manual of quantitative genetics. Washington State University Press, Washington, USA, pp. 190.

Bonham VA, Barnett JR (2001). Fibre length and microfibril angle in silver birch (Betula pendula Roth). Holzforschung 55 (2): 159-162. - doi: 10.1515/HF.2001.026

Cave ID, Walker JCF (1994). Stiffness of wood in fast-grown plantation softwoods: the influence of microfibril angle. Forest Products Journal 44 (5): 43-48. [online] URL: http://search.proquest. com/openview/95aeg00462c4fa5e00654bb817 a5eg8b/1

Cave ID (1968). The anisotropic elasticity of the plant cell wall. Wood Science and Technology 2 (4):268-278. - doi: 10.1007/BF00350273

Cave ID (1976). Modelling the structure of the softwood cell wall for computation of mechanical properties. Wood Science and Technology 10 (1): 10-28. - doi: 10.1007/BF00376381

Christophe C, Birot Y (1983). Genetic structures and expected genetic gains from multitrait selection in wild populations of douglas fir and sitka spruce. II. Practical application of index selection on several populations. Silvae Genetica 32 (5-6): 173-181. [online] URL: http://www. thuenen.de/media/institute/fg/PDF/Silvae_Gene tica/1983/Vol._32_Heft_5-6/32_5-6_173.pdf

Cui YZ, Xu ZC, Li J (1999). Variation pattern of wood nature of planted Cunninghamia lanceo- lata. Journal of Northeast Forestry University $27(5): 35-39$.

Dickmann D (2001). An overview of the genus Populus. NCR Research Press, Ottawa, Canada, pp. 1-44. [online] URL: http://www.nrcresearch press.com/doi/abs/10.1139/9780660181455

Doran J, Bush D, Page T, Glencross K, Sethy M, Viji I (2012). Variation in growth traits and wood density in whitewood (Endospermum medullosum): a major timber species in Vanuatu. International Forestry Review 14 (4): 476-485. - doi: $10.1505 / 146554812804715946$

Evans R, llic J (2001). Rapid prediction of wood stiffness from microfibril angle and density. Forest Products Journal 51 (3): 53-57.

FAO (2016). Global forest resources assessment 2015: how are the world's forests changing? $\left(2^{\text {nd }}\right.$ edn). Food and Agriculture Organization of the United Nations, Rome, Italy, pp. 54. [online] URL: http://www.fao.org/3/a-i4793e.pdf

Guan LH, Pan HX, Huang MR, Shi JS (2005). Research on growth and wood properties joint genetic improvement of new clones of Populus deltoides (1-69) × P. euramericana (1-45). Journal of Nanjing Forestry University (Natural Sciences Edition) 25 (2): 6-10.

Hannrup B (2009). Genetic variation and relationships to growth traits for microfibril angle, wood density and modulus of elasticity in a clonal trial in southern sweden. Scandinavian Journal of Forest Research 24 (6): 494-503. doi: $10.1080 / 02827580903280061$

Hernández RE, Koubaa $A$, Beaudoin $M$, Fortin $Y$ (1998). Selected mechanical properties of fastgrowing poplar hybrid clones. Wood and Fiber Science 30 (2): 138-147.

Ivkovich M (1996). Genetic variation of wood properties in balsam poplar (Populus balsamifera L.). Silvae Genetica 45 (2): 119-124.

Jonah PM (2011). Phenotypic and genotypic correlation in bambara groundnut (Vigna subterranea (L.) Verdc) in Mubi, Adamawa State, Nigeria. World Journal of Agricultural Sciences 7 (3): 298-303. [online] URL: http://www.cabdir ect.org/cabdirect/abstract/20113348718

Kärki T (2001). Variation of wood density and shrinkage in european aspen (Populus tremula). Holz als Roh- und Werkstoff 59: 79-84. doi: $10.1007 /$ s001070050479

Klasnja B, Kopitovic S, Orlovic S (2003). Variability of some wood properties of eastern cottonwood (Populus deltoides Bartr.) clones. Wood Science and Technology 37: 331-337. - doi: 10.10 07/s00226-003-0179-3

Lee SJ (1999). Improving the timber quality of sitka spruce through selection and breeding. Forestry 72 (2): 123-133. - doi: 10.1093/forestry/ 72.2.123

Li DG, Xu YJ (1994). Effect of planting density on timber density in Populus deltoides CL "Harvard". Journal of Jiangsu Forestry Science and Technology 21 (1): 6-8.

Li ZX, Li KL (2014). Geography, climate variability regularity of Populus ussuriensis Kom. growth traits. Journal of Anhui Agricultural Sciences 42 (32): 11360-11362. 11373.

Mellerowicz EJ, Baucher M, Sundberg B, Boerjan W (2001). Unravelling cell wall formation in the woody dicot stem. Plant Molecular Biology 47 (1): 239-274. - doi: 10.1023/A:1010699919325

Metougui ML, Mokhtari M, Maughan PJ, Jellen 
EN, Benlhabib O (2017). Morphological variability, heritability and correlation studies within an Argan tree population (Argania spinosa (L.) Skeels) preserved in situ. International Journal of Agriculture and Forestry 7 (2): 42-51. [online] URL: http://www.researchgate.net/publication/ 320112734

Missanjo E, Matsumura J (2017). Multiple trait selection index for simultaneous improvement of wood properties and growth traits in Pinus kesiya Royle ex Gordon in Malawi. Forests 8 (4): 96. - doi: $10.3390 / f 8040096$

Nakada R, Fujisawam Y, Taniguchi T (2005). Variations of wood properties between plus-tree clones in Larix kaempferi (Lamb.) Carriere. Bulletin of the Forest Tree Breeding Center 21: 85105.

Neale DB, Kremer A (2011). Forest tree genomics: growing resources and applications. Nature Reviews Genetics 12 (2): 111-122. - doi: 10.1038/ nrg2931

Nebgen RJ, Lowe WJ (1985). The efficiency of early and indirect selection in three sycamore genetic tests. Silvae Genetica 34 (2-3): 72-75.

Petit RJ, Hampe A (2006). Some evolutionary consequences of being a tree. Annual Review of Ecology Evolution and Systematics 37 (1): 187-214. - doi: 10.1146/annurev.ecolsys.37.09130 5.110215

Prasad AG, Al-Sagheer NA (2012). Variation in wood fibre traits among eight populations of Dipterocarpus indicus in Western Ghats, India. Journal of Environmental Biology 33 (2): 215221. [online] URL: http://search.proquest.com/ openview/6a55acea88fe930db15c65733220a02 2/1

Sharma M, Sharma CL, Kharkongor BM, Carter
MJ (2011). Wood anatomical variations in some species of Quercus of Meghalaya. Journal of the Indian Academy of Wood Science 8 (2): 152157. - doi: 10.1007/s13196-012-0057-4

Sloan S, Sayer JA (2015). Forest resources assessment of 2015 shows positive global trends but forest loss and degradation persist in poor tropical countries. Forest Ecology and Management 352 (4): 134-145. - doi: 10.1016/j.foreco.20 15.06.013

Vieira RA, Rocha R, Scapim CA, Amaral AT, Vivas $M$ (2016). Selection index based on the relative importance of traits and possibilities in breeding popcorn. Genetics and Molecular Research 15: 1-10. [online] URL: http://www.geneticsmr. com/year2016/vol15-2/pdf/gmr7719.pdf

Wang GY, Wang Y, Li SW, Qiao YL, Wang WD (2001). A study on wood physical and mechanical properties of thirteen poplar varieties. Shandong Forestry Science and Technology 2: 1-11.

Wang B, Wang JG, Jiang XY, Yin ZY (2003). Native auxiliary species of mixed broadleaf - Korean pine stands - Populus ussuriensis Kom. Forestry Science and Technology 28 (6): 12-14. [online] URL: http://en.cnki.com.cn/Article_en/ CJFDTotal-LYKJ200306004.htm

Wang GY, Zhang SH, Shi HL (2011). Excellent clonal selection of Populus ussuriensis Kom. Inner Mongolia Forestry Investigation and Design 34 (2): 20-21.

Xing XT, Zhang ZY (2004). Genetic analysis of shrinkage of new triploid clones of Populus tomentosa. Scientia Silvae Sinicae 40 (1): 137-141. [online] URL: http://europepmc.org/abstract/c $\mathrm{ba} / 359423$

Xu JR (2006). Trees quantitative genetics. China
Forestry Publishing House, Beijing, China, pp. 31-55.

Yanchuk AD, Dancik BP, Micko MM (1984). Variation and heritability of wood density and fibre length of trembling aspen in Alberta, Canada. Silvae Genetica 33 (1): 11-16.

Yu DY, Mei F, Wang JH, Zhu JL, Wang JS (2014). Joint selection for growth and wood properties in poplar hybrid clones. Journal of Northeast Forestry University 42 (2): 10-13. 16. [online] URL: http://www.cabdirect.org/cabdirect/abstr act/20143235901

Zhang LF, Jiang XM, Su XH, Zhang QW, Yu CJ (1996). A study on basic wood property of juvenile population in Ussuri poplar. Forest Research 9 (5): 517-520. [online] URL: http://euro pepmc.org/abstract/cba/296500

Zhang GQ, Zhang TW, Yang XH, Quan XC, Yao SZ (2015). General situation of breeding and growth traits investigation of Populus ussuriensis Kom in the northeast. Forestry Science and Technology 40 (3): 27-29.

Zheng YW, Li X, Lin WS (2017). Research on the wood properties of Betula platyphylla and Fraxinus mandschurica in natural secondary forest. Forest Engineering 33 (5): 35-40. [online] URL: http://en.cnki.com.cn/Article_en/CJFDTotal-SSG C201705007.htm

Zhou YL, Nie Qï S, Yuan XY, Yang FJ (1986). Flora of Heilongjiang. Northeast Forestry University Press, Harbin, China, pp. 138.

Zhou ZC, Jin GQ, Zhou SS (1994). Genetic analysis and combined selection for growth and wood quality of open-pollinated families of Masson pine. Forest Research 7 (3): 263-268. 